\title{
Educação a Distância Online e Formação de Professores: práticas de pesquisas em Educação Matemática no estado de São Paulo*
}

\author{
Distance Learning and Teachers Education: research practices in \\ Mathematics Education in São Paulo state
}

\author{
Juliana França Viol Paulin** \\ Rosana Giaretta Sguerra Miskulin ${ }^{* * *}$
}

\begin{abstract}
Resumo
Neste artigo apresentamos um mapeamento sobre Teses e Dissertações em Educação Matemática que abordam a Formação de Professores e a Educação a Distância (EaD) online. Assim, guiamo-nos segundo a perspectiva qualitativa da metanálise, sendo que os dados foram analisados sob a perspectiva teórica da Formação de Professores, bem como os procedimentos metodológicos de análise de dados foram baseados em alguns conceitos da Análise de Conteúdo. Este mapeamento crítico das Teses e Dissertações revelou seis eixos temáticos que representam as tendências de pesquisa sobre a temática investigada: Aspectos didáticopedagógicos da EaD online; Aspectos epistemológicos da EaD online; Políticas Públicas de Formação de Professores a distância; Prática Docente de professores no contexto da EaD online; Processos formativos de professores que ensinam Matemática no contexto da EaD online; e Processos de implementação de cursos de Formação de Professores a distância. Destacamos que a análise dos dados revelou que as práticas de pesquisa em Educação Matemática acerca da Formação de Professores e a EaD online está condicionada ao processo de evolução e disseminação das Tecnologias de Informação e de Comunicação (TIC) na sociedade e, consequentemente, na Educação. Além disso, foi possível identificar particularidades dos processos formativos em contextos online que revelam potencialidades da $\mathrm{EaD}$ online para a Formação de Professores.
\end{abstract}

Palavras-chave: Educação Matemática. Educação a Distância Online. Formação de Professores que Ensinam Matemática. Mapeamento. Metanálise.

\begin{abstract}
This paper presents a mapping on Mathematics Education Theses and Dissertations dealing with Teacher Education and Distance Learning. Thus, we are guided according to the qualitative perspective of meta-analysis, and the data were analyzed following procedures, which are based on some concepts of Content Analysis. This critical mapping of Theses and Dissertations revealed six themes representing the research trends on the subject investigated: didactic and pedagogical aspects of distance learning; Epistemological aspects of distance learning; Public Policy for Online Teacher Education; Practice teacher Lecturer in the context of Online learning; Formative processes of mathematics teachers in the context of Online learning and Process implementation of

\footnotetext{
* Este artigo traz um recorte da pesquisa de Doutorado desenvolvida pela primeira autora sob a orientação da segunda autora (VIOL, 2015). Esta pesquisa foi desenvolvida com o apoio financeiro da Fundação de Amparo à Pesquisa do Estado de São Paulo (FAPESP).

** Doutora em Educação Matemática pela Universidade Estadual Paulista (UNESP), Rio Claro/SP. Professora substituta do Instituto de Matemática e Estatística (IME), da Universidade Federal de Goiás (UFG), Goiânia/GO. Endereço para correspondência: Rua Manaus, 30, Apto 1404 A, Alto da Glória, Goiânia/GO, CEP 74.815-765. E-mail: viol.juliana@gmail.com

*** Doutora em Educação pela Universidade de Campinas (UNICAMP), Campinas/SP. Professora do Departamento de Educação Matemática da Universidade Estadual Paulista (UNESP), Rio Claro/SP. Endereço para correspondência: Av. 24 A, 1515, Bela Vista, Rio Claro/SP, CEP 13506-900. E-mail: misk@rc.unesp.br
} 
Online Teacher Education courses. We emphasize that the analysis of the data revealed that the research practices in mathematics education about the Teacher Education and Online learning is subject to the process of evolution and propagation of Information and Communication Technologies (ICT) in society and consequently in Education. Furthermore, it was possible to identify particular features of the formation processes in online contexts that reveal the potential of Online learning for Teacher Education.

Keywords: Mathematics Education. Online Learning. Mathematics Teacher Education. Mapping. Metaanalysis.

\section{Introdução}

Consideramos que o campo de Formação de Professores no Brasil apresenta uma compatibilidade com o processo de evolução e disseminação das Tecnologias de Informação e de Comunicação (TIC) na sociedade. Esse processo não tem apenas influenciado a formação, mas também tem contribuído para modificá-la cada vez mais. Modificar no sentido de o processo formativo acadêmico ocorrer atualmente também por meio do oferecimento de cursos a distância e de o processo formativo pessoal estar permeado pelas TIC nas práticas cotidianas.

Em outras palavras, com as TIC os processos formativos assumem uma nova dimensão, segundo Miskulin (2012), podemos considerar duas dimensões importantes proporcionadas pela comunicação e os processos formativos, viabilizados pelas TIC: a interação, que propicia o suporte à troca de informação e a comunicação entre alunos e entre alunos e professores, mantendo viva uma conexão entre as pessoas e a colaboração, que apoia o desenvolvimento de projetos e trabalhos colaborativos, possibilitando a reflexão e o desenvolvimento compartilhados de conhecimentos e significados.

Nesse sentido, acreditamos que as práticas de pesquisa em Educação Matemática têm sido fortemente influenciadas pelo movimento de introdução e disseminação das TIC nos processos de Formação de Professores. Além disso, é possível observar cada vez mais o envolvimento de pesquisadores na área de Educação Matemática que se dedicam a investigações relacionadas às potencialidades das TIC nos processos formativos e nos processos de ensino e aprendizagem da Matemática.

Por este motivo, neste artigo buscamos apresentar algumas práticas de pesquisa em Educação Matemática por meio do desenvolvimento de um mapeamento de pesquisas acadêmicas nesta área que investigaram aspectos inerentes à Formação de Professores que ensinam Matemática e a $\mathrm{EaD}$ online. Assim, este mapeamento visa elucidar as principais tendências temáticas e teórico-metodológicas que têm sido privilegiadas pelos pesquisadores, 
na intenção de sistematizar práticas de pesquisas relacionadas à EaD online e à Formação de Professores.

Para esse mapeamento buscamos por investigações produzidas e defendidas no período de 2002 a 2012, nos Programas de Pós-Graduação em Educação Matemática da Universidade Estadual Paulista (UNESP), campus Rio Claro, da Pontifícia Universidade Católica de São Paulo (PUC - SP) e da Universidade Bandeirantes de São Paulo (UNIBAN SP); no Programa de Pós-Graduação em Educação da Faculdade de Educação da Universidade de São Paulo (USP), da Faculdade de Educação da Universidade Estadual de Campinas (UNICAMP) e da Faculdade de Educação da Universidade Federal de São Carlos (UFSCar); e no Programa de Pós-Graduação em Educação para a Ciência da Universidade Estadual Paulista (UNESP), campus Bauru.

Este mapeamento foi desenvolvido por meio de um estudo exploratório-investigativo, caracterizado como metanálise (BICUDO, 2014; MELO, 2013) da produção acadêmica discente, analisando Teses e Dissertações em Educação Matemática, seguindo alguns procedimentos da perspectiva teórico-metodológica da Análise de Conteúdo (BARDIN, 1977).

\section{Aspectos teórico-metodológicos: a Metanálise e a Análise de Conteúdo como}

\section{fundamentos para a investigação}

O mapeamento que apresentamos neste artigo foi desenvolvido com base na Metanálise, modalidade de pesquisa qualitativa, segundo a perspectiva apresentada por Bicudo (2014, p. 12), visto que “[...] ao se definir um tema como significativo por responder a uma interrogação ou pergunta de fundo de uma área de investigação, buscam-se pesquisas qualitativas que tenham como alvo a investigação de aspectos desse tema e da interrogação ou pergunta formulada". Para tanto, desenvolvemos um mapeamento crítico da pesquisa que inter-relaciona aspectos inerentes à Formação de Professores que ensinam Matemática e à EaD online.

Segundo Bicudo (2014, p. 8), a raiz etimológica deste termo está na língua grega, em

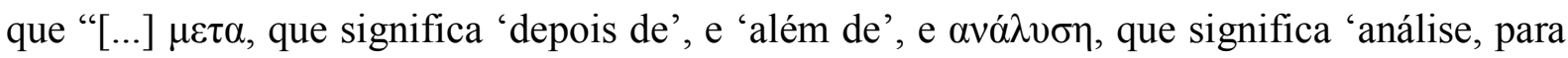
combinar os resultados" de estudos desenvolvidos por outros pesquisadores acerca da temática de interesse. Assim, pesquisas desse tipo buscam, por meio de um recorte de tempo definido, a sistematização de um determinado campo do conhecimento, objetivando 
reconhecer e identificar os principais resultados da investigação, identificar as principais tendências temáticas, assim como as abordagens dominantes e emergentes.

Trabalhando na perspectiva da pesquisa qualitativa segundo a Metanálise, após termos definido o objeto de investigação, passamos ao processo de desenvolvimento de modos de investigar esse objeto. Para a realização de nossa investigação, tomamos como objeto de análise Teses e Dissertações em Educação Matemática, que investigaram aspectos relacionados à EaD online e à Formação de Professores que ensinam Matemática. Trata-se de pesquisas acadêmicas produzidas e defendidas em programas de Pós-Graduação do estado de São Paulo ${ }^{1}$, são eles: programa de Pós-Graduação em Educação da Universidade de São Paulo (USP), da Universidade Estadual de Campinas (UNICAMP) e da Universidade Federal de São Carlos (UFSCar); Programas de Pós-Graduação em Educação Matemática da Universidade Estadual Paulista, campus de Rio Claro (UNESP - Rio Claro), da Pontifícia Universidade Católica, campus de São Paulo (PUC-SP) e da Universidade Bandeirantes de São Paulo (UNIBAN); e no Programa de Pós-Graduação em Educação para a Ciência da Universidade Estadual Paulista, campus de Bauru (UNESP - Bauru), no período de 2002 a $2012^{2}$.

Os programas de Pós-Graduação, apresentados acima, foram selecionados por meio de uma consulta aos cursos de Mestrado e Doutorado acadêmicos recomendados/reconhecidos junto à Coordenação de Aperfeiçoamento de Pessoal do Ensino Superior (CAPES).

Foram consultadas as áreas de Educação e Ensino da CAPES. A área de Educação engloba 153 cursos recomendados/reconhecidos; destes, 62 são cursos acadêmicos de Mestrado e Doutorado, com 20 cursos desenvolvidos por instituições superiores de ensino do estado de São Paulo. Destes 20 cursos, temos a identificação de 5 programas de PósGraduação em Educação Matemática; e/ou com linha de pesquisa em Educação Matemática; e/ou linha de pesquisa em Ensino de Ciências e Matemática. Porém, destes 5 programas de

\footnotetext{
${ }^{1} \mathrm{O}$ recorte espacial engloba apenas programas de Pós-Graduação do estado de São Paulo, devido ao enorme volume de pesquisas acadêmicas em Educação Matemática que são defendidas nesse estado acerca da temática investigada. Consideramos que, para o objetivo e contexto da pesquisa, as investigações desenvolvidas por programas paulistas de Pós-Graduação podem fornecer subsídios satisfatórios para o estudo e compreensão do objeto investigado. Como contribuição, outros trabalhos poderão ser realizados, abrangendo outros estados brasileiros.

${ }^{2}$ Destacamos que no recorte temporal, o período inicial deve-se aos resultados obtidos em nossa investigação de Mestrado (VIOL, 2010), uma vez que a defesa da primeira Tese, no estado de São Paulo, sobre o tema EaD e Formação de Professores ocorreu no ano de 2002, no Programa de Pós-Graduação em Educação da Universidade de São Paulo (USP). Já o período final justifica-se pelo tempo necessário para a publicação das pesquisas defendidas nas bibliotecas digitais das instituições, bem como pela necessidade de leitura de cada uma das investigações que compõem o corpus da pesquisa, na ocasião de desenvolvimento da pesquisa de Doutorado (VIOL, 2015).
} 
Pós-Graduação, apenas 4 deles possuem pesquisas desenvolvidas sobre a temática Formação de Professores e EaD online.

Assim, os programas de Pós-Graduação encontrados e que pertencem à área de Educação são: Pós-Graduação em Educação da Universidade de São Paulo (USP), da Universidade Estadual de Campinas (UNICAMP) e da Universidade Federal de São Carlos (UFSCar) e o Programa de Pós-Graduação em Educação Matemática da Universidade Estadual Paulista, campus de Rio Claro (UNESP - Rio Claro).

Já a área de Ensino engloba 111 (cento e onze) cursos recomendados/reconhecidos, trata-se de 23 (vinte e três) cursos acadêmicos de Mestrado; 3 (três) cursos acadêmicos de Doutorado; e 21 (vinte e um) cursos acadêmicos de Mestrado e Doutorado; destes cursos, 19 (dezenove) são desenvolvidos por instituições superiores de ensino do estado de São Paulo. Dos 19 (dezenove) cursos, temos a identificação de 11 (onze) programas de Pós-Graduação em Educação Matemática; e/ou com linha de pesquisa em Educação Matemática; e/ou linha de pesquisa em Ensino de Ciências e Matemática. Entretanto, destes 11 (onze) programas de Pós-Graduação, apenas 3 (três) deles têm pesquisas desenvolvidas sobre a temática Formação de Professores e EaD online.

Portanto, os programas de Pós-Graduação encontrados e que pertencem à área de Ensino são: Programa de Pós-Graduação em Educação Matemática da Pontifícia Universidade Católica, campus de São Paulo (PUC-SP), da Universidade Bandeirantes de São Paulo (UNIBAN), e do Programa de Pós-Graduação em Educação para a Ciência da Universidade Estadual Paulista, campus de Bauru (UNESP - Bauru).

Tendo encontrado os programas de Pós-Graduação, passamos ao desenvolvimento da busca pelas Teses e Dissertações a serem analisadas. A seleção das pesquisas fundamentou-se na identificação de indícios da presença da EaD e da Formação de Professores que ensinam Matemática nos seguintes elementos: título, palavras-chave, resumo e sujeitos da pesquisa. Neste contexto, consideramos pertinente destacar que nem todas as pesquisas estavam voltadas diretamente para a Formação de Professores, ou seja, não traziam explicitamente em seus títulos e/ou palavras-chave a menção da Formação de Professores, porém, com uma leitura cuidadosa dos resumos, foi possível identificar que as mesmas traziam contribuições para a Formação de Professores que ensinam Matemática, uma vez que em algumas pesquisas tínhamos como sujeitos alunos da licenciatura em Matemática, professores de Matemática e Pedagogia, e investigações acerca de aspectos inerentes à EaD.

A seguir, apresentamos a Tabela 1, que traz a distribuição de Teses e Dissertações nos referidos programas de Pós-Graduação. 
Tabela 1 - Distribuição das Teses e Dissertações por Programa de Pós-Graduação

\begin{tabular}{l|c|c|c}
\multicolumn{4}{c}{ Levantamento de Teses e Dissertações - EaD e Formação de Professores } \\
\hline \multicolumn{1}{c|}{ Instituição } & Dissertações & Teses & Total \\
\hline PUC - São Paulo & 4 & 1 & 5 \\
\hline UFSCar & 2 & 5 & 7 \\
\hline UNESP - Bauru & 1 & 0 & 1 \\
\hline UNESP - Rio Claro & 4 & 6 & 10 \\
\hline UNIBAN & 2 & 1 & 3 \\
\hline UNICAMP & 1 & 6 & 7 \\
\hline USP & 2 & 2 & 4 \\
\hline Total & $\mathbf{1 6}$ & $\mathbf{2 1}$ & $\mathbf{3 7}$
\end{tabular}

Fonte: dados da pesquisa

Para a constituição dos dados de nossa investigação, desenvolvemos a leitura de cada uma das Teses e Dissertações selecionadas. Essa leitura resultou em fichamentos que destacam os seguintes elementos: questão/problema de investigação, objetivos, referencial teórico, procedimentos metodológicos de coleta e análise de dados e principais resultados.

A análise destes fichamentos foi fundamentada em alguns procedimentos da Análise de Conteúdo (BARDIN, 1977). Nesse sentido, recriamos os passos apresentados para o desenvolvimento da Análise de Conteúdo, na busca de tornar esta metodologia de análise de dados inteligível e conveniente aos nossos objetivos, ou seja, caminhamos para uma análise interpretativa que carrega particularidades do pesquisador.

Para Bardin (1977, p. 42), a Análise de Conteúdo é

Um conjunto de técnicas de análise das comunicações visando obter, por procedimentos, sistemáticos e objetivos de descrição do conteúdo das mensagens, indicadores (quantitativos ou não) que permitam a inferência de conhecimentos relativos às condições de produção/recepção (variáveis inferidas) destas mensagens.

Nesse contexto, ao desenvolvermos a organização do material, constituído pela leitura das Teses e Dissertações, procedemos a leitura flutuante, que se caracteriza pelo estabelecimento de "[...] um contato com os documentos a analisar e em conhecer o texto deixando-se invadir por impressões e orientações" (BARDIN, 1977, p. 96).

Após a leitura flutuante, passamos à exploração do material, com o objetivo de estabelecer as unidades de contexto, unidades de registro, eixos temáticos e categorias de análise. Esses processos de exploração e análise consistem em momentos em que "[...] os resultados brutos são tratados de maneira a serem significativos (falantes) e válidos" (BARDIN, 1977, p. 101), nos conduzindo a possíveis respostas para a questão de investigação. 
Assim, passamos ao processo de identificação das unidades de contexto e unidades de registro. A unidade de registro é "[...] a unidade de significação a codificar e corresponde ao segmento de conteúdo a considerar como unidade de base, visando a categorização" (BARDIN, 1977, p. 104). Em nossa investigação, escolhemos o tema como unidade de registro, pois se trata de um tipo de unidade de registro que "[...] se liberta naturalmente de um texto analisado, segundo certos critérios relativos à teoria que serve de guia à leitura" (BARDIN, 1977, p. 105). Assim, as unidades de registro são representadas por temáticas identificadas por meio da leitura das Teses e Dissertações.

$\mathrm{O}$ processo de identificação das unidades de registro decorre das unidades de contexto. Logo, as unidades de registro pertencem à unidade de contexto, sendo que, no caso desta pesquisa, foram extraídos excertos significativos (unidades de contexto) dos dados que revelam temas (unidades de registro) pertinentes para a compreensão do objeto investigado.

Identificadas as unidades de registro, buscamos por confluências semânticas. Isso significa que procedemos ao refinamento das unidades de registro, por considerarmos que um mesmo tema e/ou ideia pode ser representado por palavras diferentes. Esse refinamento semântico das unidades de registro contribuiu para a facilitação do processo de identificação dos eixos temáticos.

Tendo procedido à identificação das unidades de registro, passamos ao processo de elencar os eixos temáticos. Esse processo é caracterizado pelo agrupamento das unidades de registro, buscando por similaridades e convergências, ou seja, recorrências temáticas.

No que segue, apresentamos os resultados inerentes ao mapeamento desenvolvido, enfatizando as principais tendências temáticas e teórico-metodológicas privilegiadas pelas investigações analisadas.

\section{Mapeamento das pesquisas que inter-relacionam a Educação a Distância Online e a}

\section{Formação de Professores que Ensinam Matemática}

Como mencionado anteriormente, o processo de desenvolvimento do mapeamento das Teses e Dissertações foi baseado na Análise de Conteúdo (BARDIN, 1977). Assim, para compor as unidades de contexto, foram extraídos dos fichamentos das Teses e Dissertações, por meio da leitura flutuante, os objetivos e problema de pesquisa (unidades de contexto) que revelam temas (unidades de registro) pertinentes à elaboração do mapeamento crítico que é desenvolvido nessa parte da análise. 
Assim, buscamos desenvolver o mapeamento das Teses e Dissertações, por meio de unidades de contexto que trazem a Questão/Problema de Investigação e os Objetivos das pesquisas analisadas. A partir da leitura flutuante e releitura dos dados, as temáticas foram se tornando mais precisas, em função dos aspectos teórico-metodológicos relacionados à $\mathrm{EaD}$ online e à Formação de Professores. Desse modo, elencamos as unidades de registro por temas, visto sua representatividade na natureza dos dados constituídos na pesquisa. A seguir apresentamos o Quadro 1 que descreve as unidades de registro (temas) relacionados à análise das Teses e Dissertações:

\begin{tabular}{|c|}
\hline $\begin{array}{c}\text { Aprendizagem de professoras iniciantes no desenvolvimento de Experiências de Ensino e Aprendizagem } \\
\text { do Programa de Mentoria }\end{array}$ \\
\hline Aprendizagem em um curso de formação continuada a distância \\
\hline $\begin{array}{c}\text { Apropriação de conhecimentos pedagógicos-tecnológicos em Matemática de professores da educação } \\
\text { básica em uma prática formativa semipresencial }\end{array}$ \\
\hline $\begin{array}{c}\text { Aspectos conceituais e instrumentais do "conhecimento da prática" docente em um curso à distância de } \\
\text { Formação de Professores }\end{array}$ \\
\hline $\begin{array}{l}\text { Aspectos teórico-práticos do processo de concepção, elaboração, planejamento, organização, implantação } \\
\text { e avaliação da Licenciatura em Pedagogia - séries iniciais do ensino fundamental na modalidade de } \\
\text { Educação a Distância }\end{array}$ \\
\hline $\begin{array}{l}\text { Condições de vida e de trabalho do professor-tutor de um curso de Formação de Professores a distância e } \\
\text { o desenvolvimento de sua prática pedagógica }\end{array}$ \\
\hline Construção de identidades online em um curso a distância \\
\hline $\begin{array}{l}\text { Contribuições de um curso de formação continuada a distância, via Internet, na perspectiva do ensino de } \\
\text { Geometria }\end{array}$ \\
\hline Desafios enfrentados pelos docentes universitários, diante das demandas do ensino superior a distância \\
\hline Diálogo na Educação Matemática a distância \\
\hline Elaboração de projetos de Modelagem ao longo de um curso a distância \\
\hline $\begin{array}{c}\text { Elaboração e a implementação de um material para a disciplina de Cálculo Diferencial e Integral do curso } \\
\text { de Licenciatura em Matemática à distância }\end{array}$ \\
\hline $\begin{array}{c}\text { Elaboração e implementação de um curso de formação continuada a distância via Internet para } \\
\text { professores de Matemática }\end{array}$ \\
\hline Experiência da Licenciatura em Educação Básica: $1^{\mathrm{a}}$ a $4^{\mathrm{a}}$ séries, através da EaD \\
\hline Exploração do processo de mediação pedagógica e do desenho educativo para cursos Web \\
\hline Formação em Matemática de alunas-professoras dos Anos Iniciais em um curso a distância de Ped \\
\hline Gestão de projetos públicos em Educação a Distância com o uso das novas tecnologias \\
\hline Impacto do curso de Pedagogia a distância na Formação de Professores em serviço \\
\hline Implantação da Educação a Distância como modalidade de ensino para a formação em Pedagogia \\
\hline $\begin{array}{l}\text { Incentivo do Ministério da Educação aos projetos de licenciatura a distância em Ciências e Matemática } \\
\text { como alternativa para suprir a carência de profissionais }\end{array}$ \\
\hline Indícios da presença das TIC nas práticas sociais dos professores em interação online \\
\hline Interações entre os participantes de um curso de Matemática a distância \\
\hline $\begin{array}{l}\text { Modelo de Formação de Professores de Matemática a distância do CEDERJ na perspectiva dos alunos e } \\
\text { dos organizadores do curso }\end{array}$ \\
\hline Natureza da aprendizagem matemática em um curso online de formação continuada em Geometria \\
\hline $\begin{array}{c}\text { Natureza da reorganização do pensamento em um curso a distância sobre tendências em Educação } \\
\text { Matemática }\end{array}$ \\
\hline $\begin{array}{c}\text { Noção de infinito dos licenciandos de Matemática, por meio da elaboração e implementação de tarefas } \\
\text { sobre sequências e séries infinitas, e sobre cardinalidade }\end{array}$ \\
\hline $\begin{array}{c}\text { Percepções e reflexões dos professores de Matemática que atuam na Educação Básica durante o processo } \\
\text { de formação continuada }\end{array}$ \\
\hline $\begin{array}{c}\text { Possibilidades e perspectivas de formar professores de Matemática na modalidade de Educação a } \\
\text { distância }\end{array}$ \\
\hline $\begin{array}{c}\text { Potencialidades didático-pedagógicas dos blogs em uma Comunidade de Prática Virtual na Formação } \\
\text { Professores de Matemática }\end{array}$ \\
\hline
\end{tabular}


Processo de formação continuada em Geometria a distância na perspectiva da prática pedagógica

Processo de transposição didática de um curso de Licenciatura em Matemática presencial para um curso ministrado a distância

Produção de conhecimentos de Professores Coordenadores de Matemática desenvolvida a partir da interação online em processo de formação continuada

Produção do conhecimento geométrico em um ambiente virtual de aprendizagem

Programa de formação continuada online para o desenvolvimento dos professores em exercício na Educação Básica

Programa formativo a distância para o desenvolvimento profissional de formadores Trabalho pedagógico do professor-mediador do curso em Pedagogia a distância

Utilização da Informática no curso normal superior a distância e uso dos laboratórios de Informática nas escolas públicas

Quadro 1 - Unidades de Registro resultantes da análise das Teses e Dissertações Fonte: dados da pesquisa

Após a identificação das unidades de registro, procedemos ao refinamento por meio das cores, que representam os eixos temáticos. Ou seja, cores iguais significam convergência da unidade de registro a um determinado eixo temático. A partir desse movimento, foi possível identificar 6 (seis) eixos temáticos, apresentados no Quadro 2:

\begin{tabular}{|c|}
\hline ASPECTOS DIDÁTICO-PEDAGÓGICOS DA EAD ONLINE \\
\hline ASPECTOS EPISTEMOLÓGICOS DA EAD ONLINE \\
\hline POLÍTICAS PÚBLICAS DE FORMAÇÃO DE PROFESSORES A DISTÂNCIA \\
\hline PRÁTICA DOCENTE DE PROFESSORES NO CONTEXTO DA EAD ONLINE \\
\hline PROCESSOS FORMATIVOS DE PROFESSORES QUE ENSINAM MATEMÁTICA NO CONTEXTO \\
DA EAD ONLINE \\
\hline PROCESSOS DE IMPLEMENTAÇÃO DE CURSOS DE FORMAÇÃO DE PROFESSORES A \\
DISTÂNCIA \\
\hline
\end{tabular}

Quadro 2 - Eixos Temáticos que constituem o mapeamento das Teses e Dissertações Fonte: dados da pesquisa

Após a identificação dos eixos temáticos, passamos ao desenvolvimento do mapeamento crítico das Teses e Dissertações, que teve por principal objetivo identificar as principais tendências temáticas e teórico-metodológicas abordadas pelas pesquisas analisadas e que abordamos a seguir.

\subsection{Eixo Temático I: aspectos didático-pedagógicos da EaD online}

No eixo temático $I$, apresentamos as pesquisas que se baseiam em diversificados objetos de investigação, mas se inter-relacionam por suas abordagens teórico-metodológicas, ao propor situações de investigações que consideram abordagens da $\mathrm{EaD}$ online e da Formação de Professores que ensinam Matemática. Elas levam em consideração aspectos inerentes à aprendizagem em ambientes virtuais de interação a distância; potencialidades desses ambientes e de outros softwares para os processos de ensino e aprendizagem da Matemática a distância; interações online; apresentação da linguagem matemática em ambientes virtuais, tanto em uma abordagem da Formação Inicial quanto da Continuada. 
Os objetos de investigação das Teses e Dissertações desse eixo podem ser identificados de acordo com o Quadro 3, abaixo:

\begin{tabular}{|c|c|}
\hline Foco/Objeto de estudo & Autor \\
\hline $\begin{array}{l}\text { Elaboração e implementação de um material para a disciplina de } \\
\text { Cálculo Diferencial e Integral II do curso de Licenciatura em } \\
\text { Matemática à distância }\end{array}$ & Forster (2007) \\
\hline $\begin{array}{c}\text { Elaboração de projetos de Modelagem por professores de Matemática } \\
\text { em um curso de formação a distância }\end{array}$ & Malheiros (2008) \\
\hline $\begin{array}{l}\text { Inter-relações existentes entre as redes comunicativas }-b l o g-\mathrm{e} \text { as } \\
\text { Comunidades de Práticas no processo de Formação de Professores }\end{array}$ & Oliveira (2012) \\
\hline Importância do diálogo para a Educação Matemática a distância & Porto (2010) \\
\hline $\begin{array}{l}\text { Natureza da aprendizagem matemática em um Curso online de } \\
\text { Formação Continuada de Professores em Geometria }\end{array}$ & Zulatto (2007) \\
\hline
\end{tabular}

Quadro 3 - Objeto/foco de investigação: Aspectos Didático-pedagógicos da EaD Online

Fonte: dados da pesquisa

Ao final da descrição das pesquisas que compõem o Eixo Temático I - Aspectos didático-pedagógicos da EaD online, identificamos investigações que tratam da Formação Inicial de professores (FORSTER, 2007) e outras que abordam a Formação Continuada de professores que ensinam Matemática (MALHEIROS, 2008; OLIVEIRA, 2012; PORTO, 2010; ZULATTO, 2007).

Essas pesquisas apresentam diferentes objetos/focos de investigações, confluindo em alguns pontos, como é o caso da investigação das potencialidades didático-pedagógicas dos ambientes virtuais de aprendizagem e demais softwares utilizados em cursos a distância, discutidas pelas pesquisas de Malheiros (2008) e Oliveira (2012). Essas investigações convergem para a análise de ambientes que propiciam a discussão de temas relacionados à Matemática a distância, destacando algumas possibilidades e dificuldades, em processos de ensinar e aprender.

Além disso, as pesquisas apresentam similaridades quanto à investigação de aspectos inerentes à aprendizagem em ambientes online e interações entre os pares, como é o caso da pesquisa desenvolvida por Zulatto (2007). Esta pesquisadora destaca que as possibilidades dos softwares e ambientes de interação a distância favorecem os processos de ensino e aprendizagem da Matemática a distância e conduzem a uma aprendizagem colaborativa.

Para Zañartu Correa (2003, p. 1), “[...] a aprendizagem colaborativa nasce e responde a um novo contexto sociocultural em que se definem o 'como aprendemos' (socialmente) e o 'onde aprendemos' (na rede)”3. Corroborando essa ideia, Miskulin e Silva (2010, p. 120) destacam que "[...] na aprendizagem colaborativa, o conhecimento é um produto social e o

\footnotetext{
${ }^{3}$ El aprendizaje colaborativo entonces, nace y responde a un nuevo contexto socio cultural donde se define el “cómo aprendemos" (socialmente) y "dónde aprendemos" (en red).
} 
processo educacional é facilitado pela interação social em um ambiente que propicia a colaboração dos colegas, a avaliação e a cooperação".

Nesse sentido, a pesquisa desenvolvida por Forster (2007) apresenta aspectos inerentes à representação da linguagem matemática em um ambiente virtual de aprendizagem e também conduz à problematização da aprendizagem colaborativa, visto que essas investigações se aproximam por apresentarem experiências e softwares/aplicativos que favorecem o processo de comunicação e/ou a linguagem matemática a distância, enfatizado suas potencialidades e apontando as contribuições para os processos de ensino e aprendizagem.

Além disso, as pesquisas de Oliveira (2012) e Zulatto (2007) apontam que o uso das TIC em cursos de formação a distância conduz a uma possível utilização das TIC na prática docente. Sobre esse aspecto, Borba (2013, p. 353-354) aponta que o uso das TIC em ambientes de ensino e aprendizagem "requer a sensibilidade do professor ou pesquisador para optar por estratégias pedagógicas que permitam explorar as potencialidades desses recursos, tornando-os didáticos", ou seja, a maneira como o professor ou pesquisador conduz as atividades que privilegiam o uso das TIC e são desenvolvidas em cursos de formação influenciará os processos de ensino e aprendizagem, bem como proporcionará aos envolvidos experienciar, no sentido de Larrosa (2002), a presença das TIC na Educação.

Também as pesquisas de Malheiros (2008) e Porto (2010) destacam que as interações ocorridas a distância propiciam momentos de diálogo e colaboração entre os pares, sendo que essas interações são potencializadas pelos ambientes em que elas ocorrem. Segundo Valente (2010, p. 26), “[...] a interação que se estabelece entre o aprendiz e outras pessoas são fundamentais para auxiliá-lo no processo de compreender o que está realizando e, com isso, construir conhecimento". Assim, com base na análise destas pesquisas, podemos inferir que o desenvolvimento das TIC propicia que os ambientes de interação a distância se tornem locais que possibilitam o "estar junto virtual", em que se estabelecem verdadeiras redes de aprendizes (VALENTE, 2010).

Já a pesquisa de Forster (2007) salienta a importância da natureza dos materiais disponíveis em cursos de formação inicial a distância. Para esses pesquisadores, os materiais online têm como principal característica a facilidade de serem acessados a qualquer momento e em qualquer lugar, com a conexão via Internet. Nesse sentido, Miskulin e Silva (2010, p. 117, grifo das autoras) apontam as características pedagógicas e computacionais dos cursos de Formação de Professores, os quais conduzem ao desenvolvimento de estratégias próprias de aprendizagem pelos alunos, ou seja, promovem o exercício da autonomia, bem como possibilitam maior flexibilidade em relação aos horários e lugares e "novas maneiras de 
incentivar o estudo individual e coletivo; além de possibilidades pedagógicas para que o aluno possa transformar em conhecimento as informações obtidas na Internet".

Assim, identificamos, com as descrições das pesquisas do eixo temático I, um discreto crescimento na pesquisa acerca da Formação de Professores que ensinam Matemática no contexto da EaD online, e enfatizamos que as pesquisas nos mostram diferentes esforços no sentido de trazer contribuições e compreensões para melhorias nos cursos de Licenciatura em Matemática a distância e para Formação Continuada de professores, bem como buscam influenciar e incentivar o desenvolvimento de políticas públicas voltadas para essa área.

\subsection{Eixo Temático II: aspectos epistemológicos da EaD online}

As pesquisas que constituem este eixo temático II trazem diferentes objetos de investigação inerentes aos processos de formação e/ou construção do conhecimento matemático em ambientes de interação/formação online. Os objetos de investigação das Teses e Dissertações podem ser identificados de acordo com o Quadro 4, abaixo:

\begin{tabular}{|c|c|}
\hline $\begin{array}{c}\text { Fspectos conceituais e instrumentais do conhecimento da prática docente do } \\
\text { professor de Cálculo Diferencial e Integral no contexto das tecnologias } \\
\text { digitais }\end{array}$ & Andriceli Richit (2010) \\
\hline $\begin{array}{c}\text { Análise das contribuições de um curso a distância, via Internet, à base de } \\
\text { conhecimento (específico e pedagógico) de professores de Matemática }\end{array}$ & Bertoluci (2007) \\
\hline $\begin{array}{c}\text { Natureza da reorganização do pensamento em um curso de formação } \\
\text { continuada a distância }\end{array}$ & Gracias (2003) \\
\hline $\begin{array}{c}\text { Noção de infinito dos licenciandos de Matemática, por meio da elaboração e } \\
\text { implementação de tarefas sobre sequências e séries infinitas, e sobre } \\
\text { cardinalidade, analisando a constituição de objetos matemáticos e as } \\
\text { interações entre participantes }\end{array}$ & Kindel (2012) \\
\hline $\begin{array}{c}\text { Construção de identidades online em um curso a distância sobre os processos } \\
\text { de ensino e aprendizagem do conceito de integral definida }\end{array}$ & Rosa (2008) \\
\hline Produção matemática de professores em um ambiente de interação a distância \\
\hline $\begin{array}{c}\text { Conhecimento desenvolvidos a partir da interação online entre Professores de } \\
\text { Matemática em um processo de formação continuada inserida em um } \\
\text { contexto de implantação de inovações curriculares no Ensino Médio }\end{array}$ & Santos (2006) \\
\hline
\end{tabular}

Quadro 4 - Objeto/foco de investigação: Aspectos Epistemológicos da EaD Online

Fonte: dados da pesquisa (data).

As pesquisas discutidas acima aproximam-se pela abordagem da construção/ressignificação do conhecimento matemático em ambientes de interação a distância. As pesquisas desenvolvidas por Gracias (2003), Rosa (2008) e Santos (2006) confluem para uma abordagem da influência das plataformas de apoio ao ensino a distância e das diferentes mídias a elas integradas no processo de construção do conhecimento matemático, ou seja, para esses pesquisadores, os ambientes virtuais e as mídias presentes nesses ambientes condicionam a forma como os sujeitos em formação discutem e elaboram 
conjecturas, e, especificamente em relação à Matemática, as mídias também transformam a produção do conhecimento matemático.

Nesse mesmo contexto, as possibilidades oferecidas pela disponibilidade das mídias digitais dos ambientes virtuais permitem que potencialidades sociais e coletivas de cada sujeito se desenvolvam e se ampliem de maneira recíproca ao longo das interações entre os pares (GRACIAS, 2003). Além disso, as interações entre os participantes dos cursos com os formadores e entre os pares, bem como a interação com as ferramentas disponíveis no ambiente, condicionam o processo de construção do conhecimento (GRACIAS, 2003; KINDEL, 2012; ROSA, 2008; SANTOS, 2006).

Essa abordagem se aproxima do estar junto virtual que está relacionado ao grau de interação entre professores e aprendizes, e entre os aprendizes.

\begin{abstract}
Essas interações permitem o acompanhamento e o assessoramento constante do aprendiz, no sentido de entender o seu interesse e o nível de conhecimento sobre determinado assunto e, a partir disso, ser capaz de propor desafios e auxiliá-lo a atribuir significado ao que está realizando. Nessa situação, ele consegue processar as informações, aplicando-as, transformando-as, buscando outras informações e, assim, construindo novos conhecimentos (VALENTE, 2011, p. 30).
\end{abstract}

As pesquisas desenvolvidas por Andriceli Richit (2010), Bertoluci (2007) e Dias (2010) também discutem a influência da interação para o processo de construção do conhecimento, porém apontam para possíveis influências na prática docente. Estas pesquisas apresentam como similaridades uma abordagem da Formação Continuada de professores de Matemática e identificam em seus resultados possíveis mudanças nas práticas docentes desses professores propiciadas pelos cursos de formação. Nessas pesquisas, a prática docente impulsiona o desenvolvimento de conhecimentos relacionados à Matemática e também conhecimentos profissionais, ou seja, os conhecimentos dos professores são (res)significados por meio da participação em cursos de formação a distância.

Novamente no Eixo Temático II - Aspectos epistemológicos da EaD online, temos a EaD online como uma possibilidade de unir professores, de aproximá-los para momentos de formação, de reflexão sobre a prática docente e de (res)significação do conhecimento profissional e matemático, bem como dos processos de ensino e aprendizagem da Matemática.

\title{
3.3 Eixo Temático III: políticas públicas de Formação de Professores a distância
}

Com o crescente desenvolvimento da EaD, temos observado diferentes iniciativas governamentais, tanto em instâncias federais e estaduais quanto municipais, para a 
mobilização de políticas públicas relacionadas à Formação de Professores a distância, principalmente em uma abordagem de formação continuada.

Não obstante esse fato, temos a realização de pesquisas científicas acerca dessa temática, que serão abordadas no eixo temático III. Abaixo, apresentamos o Quadro 5, que sistematiza os objetos de investigação de cada um dos estudos:

\begin{tabular}{|c|c|}
\hline Foco/Objeto de estudo & Autor \\
\hline $\begin{array}{l}\text { Análise de documentos oficiais e não oficiais visando mostrar a ressignificação da } \\
\text { EaD para o Ensino Superior, principalmente para a Formação de Professores }\end{array}$ & Barbosa (2010) \\
\hline $\begin{array}{l}\text { Análise da gestão de Projetos Públicos em EaD, com o uso das novas tecnologias, } \\
\text { no estado do Paraná, durante o período de } 1995 \text { a } 2005\end{array}$ & Pessoa (2006) \\
\hline
\end{tabular}

Quadro 5 - Objeto/foco de investigação: Políticas Públicas e Formação de Professores a Distância Fonte: dados da pesquisa (data).

As pesquisas desenvolvidas por Pessoa (2006) e Barbosa (2010) aproximam-se pelo fato de abordarem a análise de políticas públicas direcionadas para a Formação Inicial de professores. Elas revelam a necessidade de investimentos governamentais não apenas no financiamento de iniciativas de cursos de formação, mas também de revisão em termos de infraestrutura, organização dos cursos e formação das pessoas envolvidas (professores formadores, tutores, equipe técnica). Sobre esse aspecto, Schlemmer (2013, p. 128) destaca que, diante dessa nova modalidade educacional, "faz-se necessário refletir sobre as competências necessárias ao professor e/ou tutor na $\mathrm{EaD}$ e que precisam estar contempladas nas práticas de formação desses professores”.

As pesquisas abordam a busca pelo reconhecimento dos cursos de formação inicial a distância e não apenas o oferecimento desenfreado de licenciaturas nessa modalidade, visando sanar o problema da falta de professores para a Educação Básica. Nesse sentido, Barreto (2013, p. 142) atenta à dualidade presencial versus a distância, que "[...] materializam o esvaziamento da Formação de Professores, progressivamente deslocada para 'capacitação em serviço' ou até mesmo 'reciclagem'”. Consideramos imprescindível a análise e avaliação das políticas públicas de Formação de Professores a distância, visando o favorecimento de uma formação contextualizada e o reconhecimento dessa modalidade de formação.

Ao escrevermos sobre as políticas públicas de formação a distância de professores que ensinam Matemática, não podemos deixar de mencionar os cursos de licenciatura a distância. Nesse sentido, Miskulin (2012) apresenta-nos algumas reflexões sobre EaD, com o objetivo de contextualizar os cursos de licenciatura a distância, no cenário das políticas públicas, pontuando algumas dimensões educacionais que são intrínsecas aos cursos nessa modalidade, assim como suas potencialidades sociais, políticas e pedagógicas, tais como: “[...] o compromisso mútuo (professores e alunos), a capacidade transformadora, a autonomia, as 
exigências do mercado de trabalho, o domínio da utilização das TIC, a capacitação para a busca orientada ao conhecimento, entre outras" (MISKULIN, 2012, p. 122).

Dessa forma, os cursos de licenciatura precisam ser redimensionados, como novos espaços formativos, os quais possuem características próprias da virtualidade da comunicação mediada por computador. Nesse sentido, ao desenvolvermos a análise das pesquisas que abordam essa temática, deparamo-nos com indícios de que a EaD surgiu inicialmente com o intuito de oferecimento de cursos de licenciatura para professores em exercício da docência, ou seja, revelam uma característica assistencialista da $\mathrm{EaD}$, que visa à formação aligeirada de profissionais, e, como constatado por Mocrosky et al. (2013, p. 12), a EaD aparece "sempre lado a lado com a educação profissional entendida pelo ensino de um ofício".

Acrescentamos ainda, como destacado por Miskulin e Silva (2010, p. 114), a necessidade de se compreender qual é a "lógica implícita nas ações das políticas públicas", que nos conduz à identificação da necessidade de uma transformação dos espaços formativos, em que "[...] os alunos possam aprender e desenvolver hábitos e práticas que lhes possibilitem uma autonomia crítica, um conhecimento significativo e uma capacidade criadora".

Salientamos, por fim, a necessidade de que as Políticas Públicas de Formação de Professores a distância contemplem cada vez mais uma formação contextualizada ao ambiente de trabalho dos professores, visando a uma articulação de competências relacionadas à área específica de formação, aos aspectos didático-pedagógicos, e também priorizem o uso das tecnologias digitais.

\subsection{Eixo Temático IV: prática docente no contexto da EaD online}

O eixo temático $I V$ é constituído por investigações que abordam, de diferentes maneiras, as discussões acerca da prática docente do professor que ensina Matemática. Destacamos que essas discussões ocorrem tanto em ambientes de interação online quanto em cursos de formação continuada ou inicial a distância.

O Quadro 6, abaixo, apresenta os objetos de investigação das Teses e Dissertações que compõem este eixo:

\begin{tabular}{|c|c|}
\hline \multicolumn{1}{|c|}{ Foco/Objeto de estudo } & Autor \\
\hline $\begin{array}{c}\text { Compreensão do trabalho pedagógico do professor-mediador do curso de } \\
\text { Pedagogia para professores em exercício no início de Escolarização (PIE) }\end{array}$ & Araújo (2007) \\
\hline $\begin{array}{c}\text { Compreensão dos componentes presentes no processo de transição do ensino } \\
\text { presencial para o ensino a distância e das estratégias adotadas pela equipe de } \\
\text { professores no desenvolvimento de suas atividades }\end{array}$ & Faria (2012) \\
\hline $\begin{array}{c}\text { Análise das possibilidades e desafios da prática pedagógica do professor-tutor no } \\
\text { curso Veredas }\end{array}$ & Ferreira (2009) \\
\hline
\end{tabular}




\begin{tabular}{|c|c|}
\hline $\begin{array}{c}\text { Indícios da cultura docente presentes na interação em um curso online com o } \\
\text { olhar voltado para as práticas sociais do processo de Formação de Professores de } \\
\text { Matemática }\end{array}$ & Mariano (2008) \\
\hline $\begin{array}{c}\text { Compreensão dos desafios enfrentados pelos docentes universitários, diante das } \\
\text { demandas do ensino superior a distância, baseados em sua atuação profissional, } \\
\text { os modos de apropriação e de reinvenção da docência na EaD }\end{array}$ & Moreno (2010) \\
\hline $\begin{array}{c}\text { Análise das características do processo de Formação Continuada em Geometria } \\
\text { que permitiram ao professor repensar sua prática docente }\end{array}$ & Santos (2007) \\
\hline
\end{tabular}

Quadro 6 - Objeto/foco de investigação: Prática Docente no Contexto da EaD Online

Fonte: dados da pesquisa (data).

As pesquisas que apresentamos no Eixo Temático IV - Prática docente no contexto da $E a D$ online não convergem em seus objetos de investigação, visto que cada uma delas abordou a prática pedagógica do professor que ensina Matemática sob uma perspectiva interrelacionada com a EaD online. Mariano (2008) trata da presença das TIC na prática docente; Santos (2007) se fundamenta em um curso de formação continuada para propiciar aos professores em formação uma reflexão sobre a prática docente; Faria (2012), Moreno (2010) e Araújo (2007) investigam aspectos relacionados à prática docente do professor-formador em cursos a distância; e Ferreira (2009) discute a prática docente do professor-tutor, profissional que se faz cada vez mais presente em cursos de Formação de Professores a distância.

A aproximação das pesquisas de Mariano (2008) e Santos (2007) reside no fato de propiciarem uma formação continuada para professores que ensinam Matemática pensando em uma possível mudança e/ou ressignificação da prática docente. Nessas pesquisas, a EaD online propicia o encontro desses professores, ou seja, mais uma vez, a EaD se configura como uma possibilidade para a formação continuada de professores que ensinam Matemática.

Já as pesquisas de Araújo (2007), Faria (2012), Ferreira (2009) e Moreno (2010) analisam a prática docente na perspectiva dos diferentes atores envolvidos no processo de Formação de Professores a distância: professor-formador e professor-tutor. As pesquisas de Araújo (2007), Faria (2012) e Moreno (2010) aproximam-se pela análise da prática docente do professor-formador, pois apontam para dificuldades encontradas por esses profissionais na gestão do tempo de trabalho, uma vez que eles precisam se organizar com o trabalho em cursos presenciais e a distância; além disso, segundo as pesquisas, os professores-formadores enfrentam desafios relacionados à inserção das TIC nos cursos de formação, relacionados ao seu domínio e suas possibilidades.

Os apontamentos das pesquisas sobre a necessidade de formação para o uso das TIC também são indicados por Vanini et al. (2013, p. 156), visto que, em uma sociedade que se desenvolve segundo uma abordagem tecnológica, “o maior desconforto encontrado pelos professores [talvez] não seja a falta de instrumentos tecnológicos (todos os dias surgem 
diferentes recursos), mas o fato de tais educadores não terem uma formação tecnológica que favoreça a sua prática docente".

Também a pesquisa de Ferreira (2009), ao discutir a prática docente do professortutor, nos mostra a necessidade de cursos que visem à formação desse profissional, por considerarem que sua prática condiciona o desenvolvimento dos processos de ensino e aprendizagem dos alunos de cursos a distância. Nesse sentido, o professor-tutor é visto como "um professor que forma outros professores e de quem são exigidos os mesmos conhecimentos de um formador que atua em ambiente presencial e, também, conhecimentos específicos relacionados ao manuseio técnico e pedagógico do ambiente virtual" (ESQUINCALHA; ABAR, 2014, p. 2).

Considerando o professor-tutor como formador de professores, corroboramos as ideias de Vaillant (2003), que enfatiza o papel do formador como figura chave no desempenho profissional dos docentes. Assim, conforme a autora citada anteriormente, destacamos que o professor-tutor precisaria

[...] possuir grande experiência docente, rigorosa formação científica e didática, conhecer as principais linhas de aprendizados que as sustentam, estar apto a trabalhar com adultos e, finalmente, preparado para ajudar os docentes a realizar as mudanças comportamental, conceitual e metodológica hoje exigidas pelo sistema educativo. (VAILLANT, 2003, p. 12).

Nesse contexto, ao analisar pesquisas sobre EaD que abordam a prática docente de professores que ensinam Matemática, identifica-se a necessidade da realização de estudos que abordem aspectos relacionados à formação do tutor, visando à contribuição do reconhecimento desse profissional. Além disso, precisam ser ampliadas discussões sobre a prática docente em cursos de licenciatura em Matemática e Pedagogia, visto que não foi possível identificar nenhuma pesquisa, no universo investigado, que tratasse de aspectos inerentes à disciplina de Estágio Supervisionado, bem como à prática como componente curricular em cursos de formação inicial a distância, e identificou-se uma única investigação que voltou a atenção para a prática docente do professor-tutor.

Tratando-se da discussão acerca da prática docente em cursos de formação continuada a distância, buscam-se em Miskulin, Rosa e Silva (2009) elementos que ressaltem a importância da constituição de ambientes formativos de professores fundamentados em comunidades virtuais de aprendizagem e que privilegiem o compartilhamento de conhecimentos e práticas. Esses autores preconizam que a criação dessas comunidades se caracteriza como um grande desafio para formadores de professores, destacando que tais comunidades precisam privilegiar a transformação de informações em conhecimento crítico e 
que se "[...] possibilite produzir ações transformadoras em futuros espaços de trabalho, seja a escola ou outro lugar. Isso só poderá acontecer por meio de experiências vivenciadas e compartilhadas" (MISKULIN; ROSA; SILVA, 2009, p. 266).

Dessa forma, os cursos de Formação de Professores a distância precisam ser redimensionados, como novos espaços formativos, os quais possuam características próprias da virtualidade da comunicação mediada pelas TIC via Internet, e que privilegiem momentos de discussão acerca da prática e futura prática do professor, compartilhamento de experiências e ressignificação da prática docente.

\subsection{Eixo Temático V: processos formativos de professores que ensinam Matemática no contexto da EaD online}

As pesquisas que constituem o eixo temático $V$ apresentam diferentes objetos de investigação relacionados aos processos de Formação de Professores que ensinam Matemática, tanto em uma abordagem inicial quanto continuada. Neste eixo, o leitor poderá perceber que as pesquisas não tiveram necessariamente a $\mathrm{EaD}$ como foco de investigação, mas ela se fez presente, principalmente em iniciativas de formação continuada e formação de professores em exercício.

Os objetos de investigação das Teses e Dissertações podem ser identificados de acordo com o Quadro 7, abaixo:

\begin{tabular}{|c|c|}
\hline Foco/Objeto de estudo & Autor \\
\hline $\begin{array}{c}\text { Proposta de formação continuada semipresencial, sob a perspectiva do } \\
\text { desenvolvimento profissional docente, visando à apropriação de conhecimentos } \\
\text { pedagógico-tecnológicos em Matemática por professores da Educação Básica }\end{array}$ & Adriana Richit (2010) \\
\hline $\begin{array}{c}\text { Possibilidades e perspectivas de formar professores de Matemática na } \\
\text { modalidade de Educação a Distância }\end{array}$ & Athias (2010) \\
\hline $\begin{array}{c}\text { Análise das percepções e reflexões dos professores de Matemática que atuam na } \\
\text { Educação Básica durante o processo de formação continuada que ocorre no } \\
\text { Projeto Observatório da Educação }\end{array}$ & Campelo (2011) \\
\hline $\begin{array}{c}\text { Impacto do curso de Pedagogia a distância na formação sob a visão dos } \\
\text { professores-alunos }\end{array}$ & Cardoso (2006) \\
\hline $\begin{array}{c}\text { Investigação dos processos formativos em Matemática de alunas-professoras dos } \\
\text { Aniciais em um curso a distância de Pedagogia }\end{array}$ & Carneiro (2012) \\
\hline $\begin{array}{c}\text { Uso da Informática no contexto de formação e no contexto de trabalho de } \\
\text { professoras das séries iniciais do Ensino Fundamental participantes do Curso } \\
\text { Normal Superior Veredas }\end{array}$ & Corrêa (2005) \\
\hline $\begin{array}{c}\text { Análise das contribuições e limites de um programa a distância de formação de } \\
\text { professores-formadores à base de conhecimento de formadores, tendo em vista a } \\
\text { política de educação inclusiva }\end{array}$ & Dal-Forno (2009) \\
\hline $\begin{array}{c}\text { Proposta de formação continuada a distância para atualização de conteúdos } \\
\text { específicos de Matemática, observando aspectos referentes à aprendizagem e sua } \\
\text { influência na melhoria da prática docente }\end{array}$ & Mendes (2003) \\
\hline $\begin{array}{c}\text { Proposta de formação continuada via Internet com a abordagem do uso } \\
\text { pedagógico de planilhas de cálculo }\end{array}$ & Morgado (2003) \\
\hline
\end{tabular}




\begin{tabular}{|c|c|}
\hline $\begin{array}{c}\text { Análise de aprendizagens proporcionadas para professoras iniciantes e mentora } \\
\text { pelas Experiências de Ensino e Aprendizagem }\end{array}$ & Pieri (2010) \\
\hline $\begin{array}{c}\text { Programa de formação continuada online visando o desenvolvimento } \\
\text { profissional de professores da Educação Básica sob a perspectiva teórico- } \\
\text { metodológica da epistemologia da prática profissional e da EaD }\end{array}$ & Rinaldi (2009) \\
\hline $\begin{array}{c}\text { Proposta de formação continuada a distância em Geometria visando à análise das } \\
\text { interações entre os participantes }\end{array}$ & Socolowski (2004) \\
\hline $\begin{array}{c}\text { Análise do modelo de Formação de Professores de Matemática a distância do } \\
\text { CEDERJ na perspectiva dos alunos e dos organizadores do curso }\end{array}$ & Viel (2011) \\
\hline
\end{tabular}

Quadro 7 - Objeto/foco de investigação: Processos de Formação de Professores que Ensinam Matemática no Contexto da EaD Online

Fonte: dados da pesquisa (data).

As pesquisas apresentadas acima, e que constituem o Eixo Temático V-Processos formativos de professores que ensinam Matemática no contexto da EaD online -, apresentam algumas similaridades e divergências, principalmente no que diz respeito às constatações inerentes à Formação de Professores em ambientes virtuais. Destacamos que as pesquisas desenvolvidas por Adriana Richit (2010), Campelo (2011), Carneiro (2012), Dal-Forno (2009), Mendes (2003), Morgado (2003), Pieri (2010) e Rinaldi (2009) não tiveram como foco de investigação aspectos intimamente relacionados à $\mathrm{EaD}$ online, entretanto, essas pesquisas nos mostram que a EaD online se caracteriza como uma possibilidade para o oferecimento de cursos de formação continuada, em diferentes abordagens.

Esse apontamento vai ao encontro das considerações de Miskulin et al. (2011, p. 184), que apontam que, na EaD online, a virtualidade, constituída pelo ambiente dos cursos online, possibilita a constituição de espaços formativos de professores que ensinam Matemática, em que a colaboração emerge "como um fator essencial para a construção de significados e compartilhamentos de experiências sobre a prática docente".

Também as pesquisas de Athias (2010), Cardoso (2006), Corrêa (2005) e Viel (2011) nos mostram que a $\mathrm{EaD}$ online foi se configurando, com o passar dos anos, como uma possibilidade para o oferecimento de cursos de Formação Inicial tanto para professores em exercício, mas que ainda não possuíam formação em nível superior, quanto para aquelas pessoas distantes de grandes centros de formação e cujos munícipios não possuem cursos de licenciatura, ou até mesmo centros de formação, contribuindo, assim, para uma possível democratização do ensino superior.

Assim, a EaD online tem cooperado para o processo de democratização e acesso ao ensino superior, uma vez que tem propiciado o desenvolvimento de diferentes cursos que visam à Formação de Professores, principalmente para aqueles distantes dos grandes centros de formação. Essa democratização tem se demonstrado principalmente em relação ao oferecimento de cursos de licenciatura via $\mathrm{UAB}$, entretanto, segundo destacado por Santos 
(2011, p. 11), faz-se necessário desenvolver um mapeamento acerca das "[...] condições sociais econômicas das comunidades envolvidas e as demandas que cada região necessita", para que se possa efetivamente contribuir para uma Formação de Professores que privilegie conhecimentos específicos, pedagógicos e tecnológicos.

Quando se trata de processos de Formação de Professores que ensinam Matemática em um contexto online, inúmeros são os aspectos que surgem para a investigação, como é o caso da interação e da colaboração entre professores em formação, que são abordadas pela pesquisa de Socolowski (2004). Essas pesquisas corroboram os apontamentos de Miskulin et al. (2011, p. 176), ao tratar da virtualidade “[...] como um possível espaço formativo de colaboração entre professores". Nesse sentido, destacamos que a colaboração exerce na própria cultura docente um papel significativo quanto à reflexão sobre a constituição da cultura do ser professor, como uma de suas identidades apresentadas no próprio processo formativo. Colaborar compartilhando narrativas, fatos, problemas, experiências, anseios, expectativas e histórias de aprendizagem revela aspectos da prática docente de cada um, fato esse que pode apresentar-se como fundamental no processo de Formação do Professor que ensina Matemática.

No processo de formação a distância que privilegia a interação e a colaboração, o professor-formador caracteriza-se como um ator essencial e importante para o processo formativo, necessitando de formação para atuar nesses cursos. Esses aspectos foram investigados pelas pesquisas desenvolvidas por Dal-Forno (2009) e Pieri (2010).

Destacamos, ainda, que as pesquisas se aproximam também por similaridades em seus objetos de investigação, ao trazerem propostas de formação continuada de professores sob a perspectiva do desenvolvimento profissional docente, como é o caso de Adriana Richit (2010), Campelo (2011), Pieri (2010) e Rinaldi (2009). Trazem também propostas de formação continuada de professores, pensando no uso das TIC nos processos de ensino e aprendizagem da Matemática, como as pesquisas de Corrêa (2005), Socolowski (2004) e Adriana Richit (2010). Além disso, as pesquisas apresentam uma preocupação sobre o oferecimento de cursos de formação continuada que favoreçam a (re)construção do conhecimento matemático por parte dos professores e estejam contextualizados à sua prática docente, como as pesquisas de Mendes (2003) e Morgado (2003).

Além dos processos de formação continuada de professores, temos as pesquisas desenvolvidas por Cardoso (2006) e Viel (2011), que apresentam uma análise de cursos de formação inicial a distância de professores que ensinam Matemática, buscando compreender esses processos e apontando possíveis aspectos que podem contribuir para melhorias nos 
cursos de formação, entre os quais destacamos: a questão da identidade dos diversos profissionais envolvidos no processo formativo, visando à valorização e profissionalização docente; a importância da constituição de redes de comunicação entre os profissionais envolvidos no processo de elaboração do curso, materiais e atividades; a necessidade de uma real autonomia por parte dos alunos no desenvolvimento de atividades durante o processo formativo, ou seja, a não disponibilização de atividades que prevejam o passo a passo de desenvolvimento.

A análise das pesquisas deste eixo temático evidencia a necessidade de um redimensionamento na Formação de Professores. Baseados em Richit e Maltempi (2013, p. 242), destacamos que essa formação "é um processo amplo, dinâmico e contínuo que idealmente deveria envolver o entrelaçamento de diferentes tipos de conhecimento especializado, a saber, matemática, pedagogia e tecnologia".

\subsection{Eixo Temático VI: processos de implementação de cursos de Formação de Professores a distância}

O eixo temático VI é constituído por investigações que tiveram por objetivo analisar aspectos inerentes aos processos de organização, implementação e desenvolvimento de cursos a distância para a Formação de Professores que ensinam Matemática. As pesquisas que compõem este eixo apresentam algumas tensões e desafios que caracterizam esse processo, bem como particularidades e aspectos gerais que podem influenciar e/ou colaborar com o desenvolvimento e implementação de novos cursos a distância.

No Quadro 8, apresentamos as investigações que compõem este eixo temático, destacando os objetos/foco de estudo:

\begin{tabular}{|c|c|}
\hline \multicolumn{1}{|c|}{ Foco/Objeto de estudo } & Autor \\
\hline $\begin{array}{c}\text { Análise de uma experiência da Licenciatura em Educação Básica: } 1^{\mathrm{a}} \text { a } 4^{\mathrm{a}} \text { séries } \\
\text { através da EaD, sob suas dimensões curriculares e de gestão }\end{array}$ & Alonso (2005) \\
\hline $\begin{array}{c}\text { Organização de um curso a distância para a Formação de Professores visando } \\
\text { dimensionar uma prática de criação de cursos de Educação a Distância com o uso } \\
\text { da Internet para uma possível (res)signifinificação da Educação Continuada do } \\
\text { professor }\end{array}$ & Gomez (2002) \\
\hline $\begin{array}{c}\text { Análise de aspectos teórico-práticos do processo de concepção, elaboração, } \\
\text { planejamento, organização, implantação e avaliação da Licenciatura em Pedagogia, } \\
\text { na modalidade de EaD }\end{array}$ & Sá (2007) \\
\hline $\begin{array}{c}\text { Análise da implantação da EaD como modalidade de ensino na formação em } \\
\text { Pedagogia na UFSCar, observando a autoridade, a autonomia e o corpo presentes } \\
\text { ou ausentes nas relações pedagógicas mediadas pelas TIC }\end{array}$ & Verdan (2012) \\
\hline
\end{tabular}

Quadro 8 - Objeto/foco de investigação: Processos de implementação de cursos de Formação de Professores a Distância

Fonte: dados da pesquisa (data). 
As pesquisas que compõem o eixo temático VI abordam temáticas inerentes ao processo de constituição e desenvolvimento de cursos de Formação de Professores a distância. As investigações de Alonso (2005), Sá (2007) e Verdan (2012) se aproximam por analisarem os processos de institucionalização de cursos de Licenciatura em Pedagogia a distância. Essas pesquisas nos mostram que esse processo não reflete apenas uma mera transposição dos currículos de formação presencial para a modalidade a distância, mas sim que o processo é balizado pela concepção de currículo do curso e de modalidade de oferecimento (a distância) a que estão vinculados. Vale destacar que, segundo a pesquisa de Verdan (2012), muitas vezes a iniciativa de oferecimento de cursos a distância em uma instituição não parte do corpo docente, mas sim do corpo de gestores.

Também as pesquisas desenvolvidas por Gomez (2002) e Sá (2007) se aproximam por destacarem a importância da interação da equipe multidisciplinar que está envolvida com o processo de constituição, implementação, oferecimento e desenvolvimento dos cursos a distância. Trata-se dos designers técnicos, designers pedagógicos, professores-formadores, professores-tutores e gestores, que precisam estar em sintonia durante todo o processo, colaborando e (res)significando a prática de Formação de Professores.

Nesse sentido, Miskulin e Silva (2010, p. 118, grifo das autoras) apontam que:

\footnotetext{
Programas de educação a distância devem ser cuidadosamente 'desenhados' (designed) e gerenciados para que sejam eficientes para aprendizes: no projeto (design) devem ser previstas as suas metas gerais (perspectiva do projeto); os objetivos (perspectiva do aluno); os métodos e as estratégias; o roteiro; o projeto de interface e o suporte ao aluno. Na sua implementação, são importantes e essenciais: a produção de materiais; produção de mídias (áudio, vídeo etc.); o desenvolvimento de programas de computador; um ou dois protótipos de estudos pilotos.
}

Assim, torna-se também eminente a investigação acerca de aspectos inerentes à qualidade dos cursos de Formação de Professores que estão sendo desenvolvidos em todo o país, principalmente em uma abordagem inicial.

Ao finalizar o mapeamento das Teses e Dissertações analisadas, procedemos ao balanço das pesquisas buscando explicitar as principais tendências temáticas e teóricometodológicas que permeiam as práticas de pesquisas que versam sobre a $\mathrm{EaD}$ online e a Formação de Professores que ensinam Matemática.

\section{Considerações finais: um balanço das pesquisas que inter-relacionam a EaD online e a Formação de Professores que ensinam Matemática}


Após mapear as Teses e Dissertações, podemos traçar um panorama geral sobre os objetos de investigação privilegiados pelas pesquisas, dos quais destacamos: análise de curso de Formação Continuada a distância; possibilidades da EaD para a Formação Inicial de Professores que ensinam Matemática; aprendizagem e aprendizagem matemática em ambientes online; papel pedagógico do tutor; análise de cursos e programas de formação de formadores a distância; uso das mídias interativas em cursos online; estudo da cultura docente e uso das TIC por meio da EaD; análise de aspectos conceituais e instrumentais do conhecimento da prática de professores no contexto das TIC; construção de identidade online; elaboração de projetos de Modelagem Matemática por professores em cursos online; análise de Projetos Públicos de EaD; análise de cursos a distância de formação inicial de professores em exercício e análise do design das plataformas de apoio à $\mathrm{EaD}$.

Este mapeamento nos permite afirmar que as práticas de pesquisas em Educação Matemática que inter-relacionam aspectos inerentes à Formação de Professores que ensinam Matemática e a EaD online versam sobre os aspectos didático-pedagógicos e epistemológicos da EaD online, as políticas públicas que regulam o oferecimento de cursos de Formação Inicial e Continuada de Professores a distância, a discussão da prática docente do professor que ensina Matemática em ambientes de interação a distância, bem como tratam características e particularidades dos processos formativos de professores a distância, desde o processo de criação, implementação e desenvolvimento dos cursos de formação.

Nesse sentido, as pesquisas analisadas no Eixo Temático I - Aspectos didáticopedagógicos da EaD online discutem aspectos relacionados às potencialidades de softwares $\mathrm{e}$ ambientes de interação a distância para a discussão da Matemática online, visando a uma aprendizagem colaborativa. Além disso, as pesquisas favorecem a discussão acerca da interação e colaboração potencializada pelos ambientes, que conduzem ao compartilhamento de saberes, experiências e a uma possível (res) significação da prática docente.

Já o Eixo Temático II - Aspectos epistemológicos da EaD online - traz uma reunião de pesquisas que investigam o processo de construção do conhecimento em cursos a distância. As pesquisas privilegiam temáticas relacionadas à influência dos ambientes de interação a distância e das TIC disponíveis nos cursos para a construção e/ou (res) significação do conhecimento matemático. Além disso, as pesquisas mostram que os conhecimentos dos professores relacionados à sua formação e prática docente se tornam também um meio de refletir sobre os processos de ensino e aprendizagem da Matemática.

O Eixo Temático III - Políticas públicas de Formação de Professores a distância, que contempla apenas duas pesquisas, discute a análise de iniciativas governamentais de 
Formação Inicial de Professores, fato que se deve principalmente à falta de professores na Educação Básica. Essas pesquisas apontam para a necessidade de investimento também em recursos humanos (formação de professores-formadores e professores-tutores), visando à qualidade do processo formativo.

No Eixo Temático IV - Prática docente de professores no contexto da EaD online, foram apresentadas temáticas de investigação relacionadas à prática docente dos professoresformadores e professores-tutores em cursos de Formação Inicial e Continuada de Professores que ensinam Matemática. Além disso, outra temática que se mostrou privilegiada pelas pesquisas foi a reflexão e possível (res) significação da prática docente de professores que participam de cursos de Formação Continuada que são viabilizados pela $\mathrm{EaD}$ online.

O Eixo Temático V-Processos formativos de professores que ensinam Matemática no contexto da EaD online é contemplado por pesquisas que se preocupam com a Formação Inicial e Continuada de Professores a distância. As principais temáticas abordadas referem-se à necessidade de se repensar as propostas de formação, no sentido de oferecimento de cursos que privilegiem a integração de conhecimentos específicos, pedagógicos e tecnológicos. Além disso, as pesquisas apontam para uma possível democratização do ensino superior a partir da criação da UAB, por meio do oferecimento de cursos de formação a distância para pessoas distantes dos grandes centros de formação. Também destacamos que a virtualidade, constituída pela interação e colaboração, é apontada pelas investigações como um espaço propício à Formação de Professores.

Viol e Miskulin (2014), ao apresentarem uma reflexão teórico-metodológica acerca da prática do professor que ensina Matemática e suas inter-relações com as TIC, destacam que a participação de professores e futuros professores em situações que privilegiem experiências educativas, mediadas pelas TIC, faz com que, gradativamente, esses professores se apropriem das TIC em suas práticas cotidianas e práticas de sala de aula. Trata-se do uso das TIC de uma maneira crítica e reflexiva, que conduz às novas formas de exploração do saber matemático em sala de aula.

Já as pesquisas que compõem o Eixo Temático VI - Processos de implementação de cursos de Formação de Professores a distância trazem como principal temática investigada, as tensões presentes no processo de elaboração, implementação, oferecimento e desenvolvimento de cursos de Formação de Professores que ensinam Matemática a distância. Elas nos mostram a interação da equipe multidisciplinar responsável por esse processo, apontando para a necessidade de um trabalho colaborativo. 
Destacamos, por fim, que as pesquisas analisadas trazem como principais plataformas de ensino a distância o Moodle ${ }^{4}$, TelEduc ${ }^{5}, \mathrm{WebCT}^{6}$ e Tidia-Ae ${ }^{7}$. Entre os conteúdos matemáticos abordados, temos a Geometria e o Cálculo Diferencial e Integral. Sobre os aspectos abordados pelas pesquisas, destacamos: interação, mediação pedagógica, colaboração, papel do tutor, aprendizagem em contextos online, (res) significação da prática docente, desenvolvimento profissional, cultura docente, mídias digitais e ambientes de interação online.

No que diz respeito ao processo de Formação de Professores que ensinam Matemática a distância, a pesquisa nos mostrou aspectos relacionados à Formação Inicial que envolvem características próprias dos alunos de cursos a distância, suas dificuldades e anseios relacionados ao processo formativo. Esses alunos são capazes de construir uma identidade própria no ciberespaço e, além disso, precisam ter certa autonomia nos processos de ensino e aprendizagem e construção do conhecimento, relacionada à gestão e organização do tempo para estudo.

Ressaltamos que o processo de Formação Inicial a distância ainda sofre grande preconceito, por ser visto como uma formação aligeirada e com características de curso vago. Grande parte desse preconceito parece estar relacionado à transposição de alguns cursos de Licenciatura presenciais para a modalidade a distância, em que não são levadas em conta as particularidades de se formar professores por meio dessa modalidade.

No que se refere aos polos presenciais de apoio aos cursos a distância, foi possível identificar que alguns sofrem com precárias condições de infraestrutura, inerentes à disponibilização de livros e acesso à Internet. Também foi destacada pelas pesquisas e pelos professores/pesquisadores a grande presença de alunos nos polos, prioritariamente nas instituições particulares.

Além dos aspectos relacionados à Formação Inicial, com a análise da pesquisa pudemos refletir acerca de aspectos inerentes à Formação Continuada de professores a distância, tida como uma possibilidade de encontro entre professores advindos de diferentes contextos socioculturais e como momentos que favorecem a (res) significação da prática docente e o desenvolvimento profissional. Podemos dizer que a $\mathrm{EaD}$ online tem potencializado a constituição de comunidades de professores, que buscam (res) significar suas

\footnotetext{
${ }^{4}$ Mais informações disponíveis em: <https://moodle.org >.

${ }^{5}$ Mais informações disponíveis em: <http://www.teleduc.org.br $>$.

${ }^{6}$ Mais informações disponíveis em: <http://www.webct.com>.

${ }^{7}$ Mais informações disponíveis em: <http://www.tidia-ae.usp.br/portal〉.
} 
práticas por meio da interação e da colaboração online, bem como pela vivência no uso das TIC nos processos de ensino e aprendizagem da Matemática.

Os dados também nos mostraram que as políticas públicas voltadas à Formação de Professores a distância têm influenciado o processo de elaboração e oferecimento de cursos a distância e apontado para a necessidade de institucionalização desses cursos nas universidades envolvidas nesse processo. Entre os principais objetivos dessas políticas públicas, destacamos a democratização de acesso ao ensino superior e o atendimento à carência de professores para atuarem na Educação Básica.

Finalizamos este artigo destacando o grande desafio que permeia o campo da Formação de Professores: a promoção de contextos de ensino e aprendizagem, a criação de comunidades de aprendizagem e de investigação em que os futuros-professores e/ou os professores em Formação Continuada sejam levados a transformarem o grande número de informações disponíveis em conhecimento crítico que poderá conduzir à uma possível (res) significação da prática docente em sala de aula.

\section{Agradecimento}

Agrademos a Fundação de Amparo à Pesquisa do Estado de São Paulo (FAPESP) pelo provimento de recursos financeiros para o desenvolvimento da pesquisa de doutorado que é abordada parcialmente neste artigo.

\section{Referências}

ADRIANA RICHIT. Apropriação do Conhecimento Pedagógico-Tecnológico em Matemática e a Formação Continuada de Professores. 2010. 279 f. Tese (Doutorado em Educação Matemática) Instituto de Geociências e Ciências Exatas, Universidade Estadual Paulista, Rio Claro, 2010.

ALONSO, K. M. Formação de professores em exercício, educação a distância e a consolidação de um projeto de formação: o caso da UFMT. 2005. 322 f. Tese (Doutorado em Educação) - Faculdade de Educação, Universidade Estadual de Campinas, Campinas, 2005.

ANDRICELI RICHIT. Aspectos Conceituais e Instrumentais do Conhecimento da Prática do Professor de Cálculo Diferencial e Integral no Contexto das Tecnologias Digitais. 2010. $243 \mathrm{f}$. Dissertação (Mestrado em Educação Matemática) - IGCE, Universidade Estadual Paulista, Rio Claro, 2010.

ARAÚJO, I. A. Textos, Contextos e Intertextos do Trabalho Pedagógico do(a) Professor Mediador(a) no Curso PIE/FE-UnB. 2007. 331 f. Tese (Doutorado em Educação) - Faculdade de Educação, Universidade Estadual de Campinas, Campinas, 2007.

ATHIAS, M. F. Licenciatura em Matemática na modalidade de educação a distância: um desafio para a formação de professores. 2010. 214 f. Dissertação (Mestrado em Educação Matemática) Pontifícia Universidade Católica, São Paulo, 2010. 
BARBOSA, A. P. L. A ressignificação da Educação a Distância no Ensino Superior do Brasil e a Formação de Professores de Ciências e Matemática. 2010. 294 f. Dissertação (Mestrado em Educação) - Faculdade de Educação, Universidade de São Paulo, São Paulo, 2010.

BARDIN, L. Análise de Conteúdo. Lisboa: Edições 70, 1977.

BARRETO, R. G. Formação de professores a distância: políticas e práticas. In: GATTI, B. A.; SILVA JUNIOR, C. A.; PAGOTTO, M. D. S.; NICOLETTI, M. G. (Org.). Por uma política nacional de formação de professores. São Paulo: Editora UNESP, 2013. p. 137-149.

BERTOLUCI, E. A. Formação continuada online de professores dos anos iniciais: contribuições para a ampliação da base de conhecimento para o ensino de geometria. 2007. 385 f. Tese (Doutorado em Educação) - Universidade Federal de São Carlos, São Carlos, 2007.

BICUDO, M. A. V. Meta-análise: seu significado para a pesquisa qualitativa. REVEMAT - Revista Eletrônica de Educação Matemática, Florianópolis, v. 9, p. 7-20, jun. 2014. Disponível em: <https://periodicos.ufsc.br/index.php/revemat/article/viewFile/1981-1322.2014v9nespp7/27377>. Acesso em: 27 out. 2014.

BORBA, M. C. Educação Matemática a Distância Online: balanço e perspectivas. Cuadernos de Investigación y Formación Matemática, Costa Rica, ano 8, n. 11, p. 349-358, 2013.

CAMPELO, N. C. S. Investigando percepções e desvelando reflexões do professor de matemática no processo de formação continuada. 2011. 147 f. Dissertação (Mestrado em Educação Matemática) - Universidade Bandeirantes de São Paulo, São Paulo, 2011.

CARDOSO, J. G. Curso de Pedagogia para os Anos Iniciais do Ensino Fundamental na Modalidade a Distância: pactos e impactos. 2006. 248 f. Tese (Doutorado em Educação) - Faculdade de Educação, Universidade Estadual de Campinas, Campinas, 2006.

CARNEIRO, R. F. Processos formativos em matemática de alunas-professoras dos anos iniciais em um curso a distância de Pedagogia. 2012. 308 f. Tese (Doutorado em Educação) - Universidade Federal de São Carlos, São Carlos, 2012.

CORREAA, J. Do laboratório de informática as páginas web: ambientes virtuais e contextos escolares. 2005. 165 f. Tese (Doutorado em Educação) - Faculdade de Educação, Universidade Estadual de Campinas, Campinas, 2005.

DAL-FORNO, J. P. Formação de Formadores e Educação Inclusiva: análise de uma experiência via internet. 2009. 319 f. Tese (Doutorado em Educação) - Universidade Federal de São Carlos, São Carlos, 2009.

DIAS, F. A. S. Educação Online e Formação Continuada de Educadores: uma investigação sobre interação em um curso para professores de Matemática do Ensino Médio. 2010. 182 f. Dissertação (Mestrado em Educação Matemática) - Universidade Bandeirantes de São Paulo, São Paulo, 2010.

ESQUINCALHA, A. C.; ABAR, C. A. A. P. Contribuições para Formação de Tutores de Cursos a Distância para Professores de Matemática. In: FÓRUM GT 6 - SBEM - EDUCAÇÃO MATEMÁTICA: NOVAS TECNOLOGIAS E EDUCAÇÃO A DISTÂNCIA, 2., 2014, Rio de Janeiro. Anais... Rio de Janeiro: SBEM, 2014, p. 1-8. Disponível em: <http://media.wix.com/ugd/b40184_9bb04dd7f6f04c36bd9eb2c9e18c03b4.pdf>. Acesso em: 01 out. 2014. 
FARIA, E. C. Do Ensino Presencial ao Ensino a Distância: a inovação na prática pedagógica de professores de Matemática. 2012. 154 f. Tese (Doutorado em Educação Matemática) - Faculdade de Ciências Exatas e Tecnologia, Pontifícia Universidade Católica de São Paulo, São Paulo, 2012.

FERREIRA, Z. M. Prática pedagógica do professor-tutor em educação a distância no curso Veredas - Formação Superior de Professores. 2009. 312 f. Tese (Doutorado em Educação) Faculdade de Educação, Universidade de São Paulo, São Paulo, 2009.

FORSTER, S. R. Ensino a Distância: uma análise do design de um curso de Cálculo com um olhar no conteúdo de limites e continuidade de uma variável real. 2007. 288 f. Dissertação (Mestrado em Educação Matemática) - Pontifica Universidade Católica, São Paulo, 2007.

GOMEZ, M. V. Educação em Rede: o processo de criação de um curso web. 2002. Tese (Doutorado em Educação) - Faculdade de Educação, Universidade de São Paulo, São Paulo, 2002.

GRACIAS, T. A. S. A Natureza da Reorganização do Pensamento em um Curso a Distância sobre "Tendências em Educação Matemática". 2003. 167 f. Tese (Doutorado em Educação Matemática) - Instituto de Geociências e Ciências Exatas, Universidade Estadual Paulista, Rio Claro, 2003.

KINDEL, D. S. Um Ambiente Colaborativo a Distância: Licenciandos Dialogando sobre os Infinitos. 2012. 280 f. Tese (Doutorado em Educação Matemática) - Universidade Bandeirantes de São Paulo, São Paulo, 2012.

LARROSA, J. Notas Sobre a Experiência e o Saber de Experiência. Tradução: J. W. Geraldi. Revista Brasileira de Educação, São Paulo, n. 19, p. 20-28, jan./abr. 2002.

MALHEIROS, A. P. S. Educação matemática online: a elaboração de projetos de modelagem. 2008. 187 f. Tese (Doutorado em Educação Matemática) - Instituto de Geociências e Ciências Exatas, Universidade Estadual Paulista, Rio Claro, 2008.

MARIANO, C. R. Indícios da Cultura Docente Revelados em um Contexto Online no Processo da Formação de Professores de Matemática. 2008. 162 f. Dissertação (Mestrado em Educação Matemática) - Instituto de Geociências e Ciências Exatas, Universidade Estadual Paulista, Rio Claro, 2008.

MELO, M. V. As Práticas de Formação no Estágio Curricular Supervisionado na Licenciatura em Matemática: o que revelam as pesquisas acadêmicas brasileiras na década 2001-2010. 2013. 396 f. Tese (Doutorado em Educação) - Faculdade de Educação, Universidade Estadual de Campinas. Campinas, 2013.

MENDES, R. A. V. Avaliação de um Curso de Educação a Distância para a Formação Continuada de Professores de Matemática. 2003. 152 f. Dissertação (Mestrado em Educação para Ciências) - Faculdade de Ciências, Universidade Estadual Paulista, Bauru, 2003.

MISKULIN, R. G. S. Mito seis. Es sólo para ciertos temas. In: LÓPEZ, G. A. V.; BRAVO, M. L. R. (Ed.). Diez mitos sobre la educación virtual: una mirada intercultural. Medellín: Fondo Editorial Universidad, 2012. p. 101-124.

MISKULIN, R. G. S.; ROSA, M.; SILVA, M. R. C. Comunidade de Prática Virtual: possíveis contribuições para a formação de professores de matemática. In: FIORENTINI, D.; GRANDO, R. C.; MISKULIN, R. G. S. (Org.). Práticas de Professores que Ensinam Matemática. Campinas: Mercado das Letras, 2009. p. 257-278 
MISKULIN, R. G. S.; SILVA, M. R. C. Curso de Licenciatura em Matemática a Distância: uma realidade ou uma utopia?. In: JAHN, A. P.; ALLEVATTO, N. S. G. (Org.). Tecnologias e Educação Matemática: ensino, aprendizagem e formação de professores. Recife: SEBEM, 2010. p. 105-124.

MOCROSKY, L. F. et al. Educação a Distância na Legislação Brasileira: um estudo interpretativo do marco legal. In: ENCONTRO NACIONAL DE EDUCAÇÃ̃O MATEMÁTICA, 11., 2013, Curitiba. Anais... Curitiba: Sociedade Brasileira de Educação Matemática, 2013, p. 1-14. Disponível em: <http://sbem.bruc.com.br/XIENEM/>. Acesso em: 21 out. 2013.

MORENO, E. R. Desafios da docência em cursos de pedagogia a distância. 2010. 145 f. Dissertação (Mestrado em Educação) - Faculdade de Educação, Universidade Estadual de Campinas, Campinas, 2010.

MORGADO, M. J. L. Formação de Professores de Matemática para o Uso Pedagógico de Planilhas Eletrônicas de Cálculo: análise de um curso a distância via internet. 2003. 252 f. Tese (Doutorado em Educação) - Universidade Federal de São Carlos, São Carlos, 2003.

OLIVEIRA, M. A. O. As Possíveis Inter-relações das redes comunicativas - Blogs - e das Comunidades de Prática no Professor de Formação de Professores de Matemática. 2012. 206 f. Dissertação (Mestrado em Educação Matemática) - Instituto de Geociências e Ciências Exatas, Universidade Estadual Paulista, Rio Claro, 2012.

PESSOA, M. P. A gestão de projetos públicos de educação a distância no Paraná (1995-2005): contradições e perspectivas. 2006. 260 f. Tese (Doutorado em Educação) - Faculdade de Educação, Universidade Estadual de Campinas, Campinas, 2006.

PIERI, G. S. Experiências de Ensino e Aprendizagem: estratégia para a formação online de professores iniciantes no Programa de Mentoria da UFSCar. 2010. 177 f. Dissertação (Mestrado em Educação) - Universidade Federal de São Carlos, São Carlos, 2010.

PORTO, J. F. Diálogo e interatividade em videoaulas de matemática. 2010. 133 f. Dissertação (Mestrado em Educação) - Faculdade de Educação, Universidade de São Paulo, São Paulo, 2010.

RICHIT, A.; MALTEMPI, M. V. Pesquisas em Formação Inicial e Continuada de Professores: percursos e concepções emergentes. In: BORBA, M. C.; CHIARI, A. (Org.). Tecnologias Digitais e Educação Matemática. São Paulo: Livraria da Física, 2013. p. 221-250.

RINALDI, R. P. Desenvolvimento profissional de formadores em exercício: contribuições de um programa online. 2009. 231 f. Tese (Doutorado em Educação) - Universidade Federal de São Carlos, São Carlos, 2009.

ROSA, M. A construção de identidades online por meio do Role Playing Game: relações do ensino e aprendizagem de matemática em curso a distância. 2008. 263 f. Tese (Doutorado em Educação Matemática) - Instituto de Geociências e Ciências Exatas, Universidade Estadual Paulista, Rio Claro, 2008.

SÁ, R. A. Educação a distância: estudo exploratório e analítico de curso de graduação na área de formação de professores. 2007. 422 f. Tese (Doutorado em Educação) - Faculdade de Educação, Universidade Estadual de Campinas, Campinas, 2007.

SANTOS, F. C. UAB como Política Pública de Democratização do Ensino Superior via EaD. In: SIMPÓSIO BRASILEIRO DE POLÍTICA E ADMINISTRAÇÃO DA EDUCAÇÃO, 25., 2011, São Paulo. Anais... São Paulo: ANPAE, 2011, p. 1-13. Disponível em:

<http://www.anpae.org.br/simposio2011/cdrom2011/PDFs/trabalhosCompletos/comunicacoesRelatos/ 0184.pdf>. Acesso em: 01 out. 2014. 
SANTOS, J. A. Formação Continuada de Professores em Geometria por meio de uma

Plataforma de Educação a Distância: uma experiência com professores de Ensino Médio. 2007. 187

f. Dissertação (Mestrado em Educação Matemática) - Pontifica Universidade Católica, São Paulo, 2007.

SANTOS, S. C. A Produção Matemática em um Ambiente Virtual de Aprendizagem: o caso da Geometria Euclidiana Espacial. 2006. 145 f. Dissertação (Mestrado em Educação Matemática) Instituto de Geociências e Ciências Exatas, Universidade Estadual Paulista, Rio Claro, 2006.

SCHLEMMER, E. Políticas e práticas de formação de professores a distância: por uma emancipação digital cidadã. In: GATTI, B. A. et al.(Org.). Por uma política nacional de formação de professores. São Paulo: Editora UNESP, 2013. p. 109-136.

SOCOLOWSKI, R. C. A. J. Análise das Interações Tutor/Participantes: um ponto de partida para avaliação de cursos de desenvolvimento profissional a distância. 2004. 129 f. Dissertação (Mestrado em Educação Matemática) - Pontifica Universidade Católica, São Paulo, 2004.

VAILLANT, D. Formação de Formadores: Estado da Prática. Rio de Janeiro: PREAL, 2003. Disponível em:

<http://www.oei.es/docentes/articulos/formacion_formadores_estado_practica_vaillant_portugues.pdf >. Acesso em: 01 out. 2014.

VALENTE, J. A. O papel da interação e as diferentes abordagens pedagógicas de Educação a Distância. In: MILL, D. R. S.; PIMENTEL, N. R. Educação a Distância: desafios contemporâneos. São Carlos: EdUFSCar, 2010. p. 25-42.

VALENTE, J. A. Educação a Distância: criando abordagens educacionais que possibilitam a construção de conhecimento. In: ARANTES, V. A. (Org.). Educação a Distância: pontos e contrapontos. São Paulo: Summus, 2011. p. 13-44.

VANINI, L. et al. Cyberformação de Professores de Matemática: olhares para a dimensão tecnológica. Acta Scientiae, Canoas, v. 15, n. 1, p. 153-171, jan./abr. 2013.

VERDAN, K. C. S. A Educação a Distância e a formação de professores na UFSCar: a autoridade, a autonomia e o corpo mediados pelas Tecnologias da Informação e Comunicação. 2012. 166 f. Dissertação (Mestrado em Educação) - Universidade Federal de São Carlos, São Carlos, 2012.

VIEL, S. R. Um Olhar Sobre a Formação de Professores de Matemática a Distância: o caso do CEDERJ/UAB. 2011. 218 f. Tese (Doutorado em Educação Matemática) - Instituto de Geociências e Ciências Exatas, Universidade Estadual Paulista, Rio Claro, 2011.

VIOL, J. F. Movimento das Pesquisas que Relacionam as Tecnologias de Informação e de Comunicação e a Formação, a Prática e os Modos de Pensar de Professores que Ensinam Matemática. 2010. 223 f. Dissertação (Mestrado em Educação Matemática) - Instituto de Geociências e Ciências Exatas, Universidade Estadual Paulista, Rio Claro, 2010.

VIOL, J. F. P. Educação a distância online: potencialidades para a Formação de Professores que ensinam Matemática. 2015. 269 f. Tese (Doutorado em Educação Matemática). Instituto de Geociências e Ciências Exatas, Universidade Estadual Paulista, Rio Claro, 2015.

VIOL, J. F. P.; MISKULIN, R. G. S. As Práticas do Professor que Ensina Matemática e suas Interrelações com as Tecnologias Digitais. Revista e-Curriculum, São Paulo, v. 2, n.12, p. 1-20, maio/out. 2014. 
ZAÑARTU CORREA, L. M. Aprendizaje colaborativo: uma nueva forma de Diàlogo Interpersonal y em Red. Contexto Educativo, Buenos Aires, v. 28, p. 1-12, 2003. Disponível em:

<http://tic.sepdf.gob.mx/micrositio/micrositio2/archivos/AprendizajeColaborativo.pdf >. Acesso em: 30 set. 2014.

ZULATTO, R. B. A. A Natureza da Aprendizagem Matemática em um Ambiente Online de Formação Continuada de Professores. 2007. 174 f. Tese (Doutorado em Educação Matemática) Instituto de Geociências e Ciências Exatas, Universidade Estadual Paulista, Rio Claro, 2007.

Submetido em Abril de 2015. Aprovado em Setembro de 2015. 